\title{
US plays hide-and-seek with Soviets on missile sites
}

\section{David Dickson describes a new plan for nuclear deployment}

Clausewitz would no doubt have admired the latest move by US defence officials, who are considering plans for a giant $\$ 30$ billion "shell and pea" game in which the Soviet Union, if it wants to destroy a particular nuclear missile. would have to guess which of 20 launching holes contained the missile.

The plan, in which the silos would be three to five miles apart, is currently enjoying high favour in Washington military circles as a method for deploying the next generation of intercontinental ballistic missiles, known as MX (for missile experimental). Soviet missiles are now reported to have an accuracy of 600 feet. and it is claimed that such a shell game would avoid the consequent vulnerability of fixed launchers, without significantly increasing the number of missiles deployed.

However there are indications that plans to proceed with what is officially known as a Multiple Aim Point (MAP) deployment scheme could effect the progress of the current Strategic Arms Limitations Talks (SALT 2), now taking place between the US and the USSR in Geneva, since the Soviet Union is concerned over whether the scheme could be adequately verified.

An earlier idea of deploying the MX missiles in a system of tunnels 12 to 15 miles long. along which the missiles could be moved as desired, has now been abandoned following criticism from both within and outside the Defense Department (including a study chaired by the President's science adviser, Dr Frank Press) of the costs involved, and the fear that such a scheme would remain vulnerable to Soviet attack.

However evidence that the USSR has considerably closed the technological gap with the US since the original SALT agreement of 1972 is being used by Defense Department chiefs, backed by powerful industrial interests, as an opportunity to gather support for the shell game idea. In his first press conference as chaiman of the joint chief of staffs, for example. Air Force General David C. Jones said last week that this was "the most attractive way" of protecting landbased missiles.

A number of different variations of the MAP scheme have been closely studied in order to determine the most effective. In addition to the now-discarded tunnel scheme, three others were studied involving the transportation of missiles between different launching sites: one scheme using vertical shelters, a second using cheaper, but more vulnerable, horizontal shelters, and a third launching the missile from under a pool of water.

The system thought to be most favoured by the Air Force is that involving vertical shelters. The missile would be transported and stored within a canister, and would be launched from the canister using compressed gas before its first stage engine was fired.

The canister would be moved periodically between 20 and 25 differant vertical shelters, and empty canisters might also be moved around as decoys. The Soviets would therefore have to target warheads at each of the shelters to be certain of eliminating the missile; and Defense Department offi-

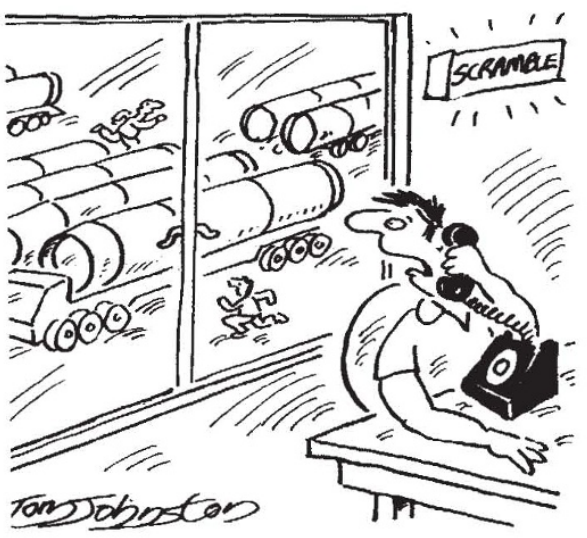

"We would fire it, Mr President, but we can't find it.'

cials claim that the cost of each warhead to the USSR would be significantly higher than the cost of each shelter to the US.

Members of Congress are keen to press ahead with the development of a mobile missile system. and are even suggesting that, since $\mathrm{MX}$ is unlikely to be deployed until the mid-1980s, a similar scheme known as alternative launch point (ALP) should in the meantime be developed for the existing Minuteman missiles. Given the increasing accuracy of Soviet missiles, the present Minuteman siloes distributed throughout the country will, it is claimed. soon be vulnerable to attack.

Others, however, are critical of the whole MAP scheme. "The notion that MAP provides an effective response to improved Soviet military technology falls into the fallacy of the last move. ignoring the likely response," according to Dr Michael Nacht, assistant director of the Program for Science and International Affairs at Harvard University. "If we build 20.000 holes for 1,000 missiles, and the Soviets then build 10,000 holes each capable of holding a MIRVed (multiple intercontinental re-entry vehicle) missile with eight war-heads, how can we be sure that they do not cheat and confront us with 80.000 warheads?"

Further concern has been raised about the environmental impact of the scheme. A report published by the Air Force two weeks ago predicted that the total area required for full deployment of an MX force would be about 6,000 square miles, about the size of the Statc of Connecticut, and could be considerably more. In addition. the missile on its trailer would weigh over 500,000 pounds, and transporting the missile between different shelters would therefore make it necessary to strengthen large numbers of existing roads and bridges, currently designed to carry only $120,000 \mathrm{lb}$

The Carter administration is now having to decide whether to press ahead with the next stage of the MAP scheme. a full-scale engineering development estimated to cost about $\$ 5$ billion over five years, or whether to concentrate its research efforts on strengthening the two other areas of missile delivery systems, the sea-land ballistic missile (SLBM) and long-range bombers.

The most immediate concern, however, is the impact of MAP schemes on the current SALT 2 talks. At present. proposals are being discussed for a three-year protocol agreed between the US and the USSR, which would accept mobile missile systems, but ban their deployment and flight testing from operational launchers.

At the same time President Carter has told the Soviets that, barring further agreement, the US reserves the right to deploy a mobile missile system in the post-protocol period-a position which the president feels necessary if a new SALT treaty lasting through to 1985 is to get the approval of Congress.

The Soviet response to this has been cool. While not ruling out the deployment of a mobile missile system under the new treaty, the chief Soviet arms negotiator. Vladimir S. Semyonov, has raised questions about the acceptability of the MAP system, in particular the difficulty that the USSR would have in verifying the total number of US missiles deployed at any one time.

"I don't think that a system of arms control based on verification is compatible with a system of missile deployment based on deception. And the implication is that either you have SALT. or you have MAP"', according to Dr Nacht. Or perhaps you recruit your chess players as defence analysts. and give the World Championship a new meaning. 